\title{
Reward, memory and prediction of treatment response in affective disorders
}

\author{
Andrea Schmitt $\cdot$ Peter Falkai
}

Published online: 11 March 2014

(c) Springer-Verlag Berlin Heidelberg 2014

The reward system has been reported to be affected in patients with major depression or anhedonia and has been viewed as a symptom expressed by deficits in experiencing proper reward. In a sample of first-episode and multipleepisode patients with major depression plus healthy controls, Hall et al. [1] for the first time compared functional magnetic resonance imaging (fMRI) during performance of a contingency reversal reward paradigm. They detected group differences in orbitofrontal and medial prefrontal regions. Additionally, nucleus accumbens, anterior cingulate and ventral prefrontal cortices were most activated in healthy controls, less in patients with one-episode and least in multiple-episode patients. Those brain areas may be sensitive to neurobiological alterations during repeated episodes of depression. While impaired cognition and decreased volumes of the hippocampus repeatedly have been reported for patients with major depression, bipolar patients present inconsistent structural imaging data possibly due to lithium therapy. Using a transitive inference (TI) paradigm suitable for assessing relational memory performance and fMRI, Avery et al. [2] examined hippocampal activity and hippocampal volumes via manual segmentation in patients with bipolar disorder compared to healthy controls. They found no differences in any of these parameters between both groups but very well a positive correlation between hippocampal volume and relational memory performance. These results possibly distinguish bipolar disorder from schizophrenia without consulting a

A. Schmitt $(\square)$. P. Falkai

Department of Psychiatry and Psychotherapy, Ludwig-

Maximilians-University Munich, Nußbaumstr. 7, 80336 Munich, Germany

e-mail: andrea.schmitt@med.uni-muenchen.de common neurogenetic background, which confirms recent genome-wide association studies.

Low-resolution brain electromagnetic tomography is a neuroelectric brain imaging technique based on electroencephalography (EEG), which Rentzsch et al. [3] used in combination with assessing symptoms improvement after 4 weeks of antidepressant therapy in patients with major depression to predict treatment response. Responders showed more slow-frequency power in the right anterior cingulate cortex compared to non-responders which the authors attribute to antidepressant treatment response. In a structural MRI analysis, Segalàs et al. [4] found the left anterior cingulate cortex and medial orbital gyrus to be enlarged in patients with obsessive-compulsive disorder (OCD) compared to healthy controls. Interestingly, determined olfactory dysfunctions could be correlated with gray matter of the anterior cingulate cortex. This brain region receives projections from primary olfactory regions and such alterations should be assessed in other patients groups with known olfactory dysfunction (e.g., mood disorders or schizophrenia).

An epidemiological Swedish study by Lejtzén et al. [5] depicts prevalence and incidence of mood disorders, anxiety disorders and stress and adjustment disorders in primary health care. The 12-month prevalence of these disorders averaged $2.4 \%$ plus an incidence of $18.4 \%$ per 1,000 person years. Strongest socio-demographic risk factors were female gender, low family income, living in a large city and age 35-44 years. Many patients with affective disorders have difficulties in regaining premorbid functional levels and some of them exert poor work adjustment. Bonnín et al. [6] investigated a sample of bipolar I euthymic patients using a neuropsychological test battery and a work-focused interview. The highest statistically significant contribution to poor work adjustment 
correlated with the number of manic episodes and number of perseverative errors in the Wisconsin Card Sorting Test (WCST), explaining up to $36 \%$ of the variance. These results point to the impact of prevention of relapse and the need for finding improved neurocognitive enhancement therapeutic strategies in severe psychiatric disorders.

Electroconvulsive therapy is a highly effective treatment option for specific forms of affective disorders, but choice of the narcotic agent may influence seizure quality and clinical outcome. In a large group of anesthesias, Hoyer et al. [7] compared retrospectively ketamine, etomidate, thiopental and propofol as anesthetics with respect to their influence on seizure quality and parameters. They report advantageous effects of ketamine and etomidate in seizure quality and duration of motor seizure activity compared to thiopental and propofol. Ketamine had the most favorable central inhibitory potential. These findings should be considered when planning ECT sessions in severely affected patients. In elderly patients, differential diagnosis between depression and dementia is often difficult and impacts treatment decisions. Polak et al. [8] showed prolonged latencies of vagus somatosensory-evoked potentials (VSEP) in patients with Alzheimer's disease compared to patients with major depression and age-matched healthy controls. Cause is possibly a degeneration of brainstem nuclei in Alzheimer's disease for which reason evaluation of VSEP possibly contributes to differ between both diagnoses.

\section{References}

1. Hall GB, Milne AM, MacQueen GM (2013) An fMRI study of reward circuitry in patients with minimal or extensive history of major depression. Eur Arch Psychiatry Clin Neurosci. doi:10.1007/ s00406-013-0437-9

2. Avery SN, Williams LE, Woolard AA, Heckers S (2013). Relational memory and hippocampal function in psychotic bipolar disorder. Eur Arch Psychiatry Clin Neurosci. doi:10.1007/s00406013-0442-z

3. Rentzsch J, Adli M, Wiethoff K, de Castro AGC, Gallinat J (2013) Pretreatment anterior cingulate activity predicts antidepressant treatment response in major depressive episodes. Eur Arch Psychiatry Clin Neurosci. doi:10.1007/s00406-013-0424-1

4. Segalàs $\mathrm{C}$, Alonso $\mathrm{P}$, Orbegozo $\mathrm{A}$, Real $\mathrm{E}$, Subirà $\mathrm{M}$, López-Solà C, Martínez-Zalacaín I, Labad J, Harrison BJ., Pujol J, Menchón JM, Cardoner N, Soriano-Mas C (2013) Brain structural imaging correlates of olfactory dysfunction in obsessive-compulsive disorder. Eur Arch Psychiatry Clin Neurosci. doi:10.1007/s00406013-0439-7

5. Lejtzén N, Sundquist J, Sundquist K, Li X (2013) Depression and anxiety in Swedish primary health care: prevalence, incidence, and risk factors. Eur Arch Psychiatry Clin Neurosci. doi:10.1007/ s00406-013-0422-3

6. Bonnín CM, Torrent C, Goikolea JM, Reinares M, Solé B, Valentí M, Sánchez-Moreno J, Hidalgo D, Tabarés-Seisdedos R, MartínezArán A, Vieta E (2013) The impact of repeated manic episodes and executive dysfunction on work adjustment in bipolar disorder. Eur Arch Psychiatry Clin Neurosci. doi:10.1007/s00406-013-0431-2

7. Hoyer C, Kranaster L, Janke C, Sartorius A (2013) Impact of the anesthetic agents ketamine, etomidate, thiopental, and propofol on seizure parameters and seizure quality in electroconvulsive therapy: a retrospective study. Eur Arch Psychiatry Clin Neurosci. doi:10.1007/s00406-013-0420-5

8. Polak T, Dresler T, Zeller JB, Warrings B, Scheuerpflug P, Fallgatter AJ, Deckert J, Metzger FG (2013) Vagus somatosensory evoked potentials are delayed in Alzheimer's disease, but not in major depression. Eur Arch Psychiatry Clin Neurosci. doi:10.1007/ s00406-013-0415-2 